\title{
The NSF and the Geosciences
}

\section{Community: Rotating Program Officers}

PAGES 801, 808, 810-811

\section{Rodey Batiza}

Department of Geological Sciences,

Northwestern University, Evanston, Illinois

\section{David K. Rea}

Department of Geological Sciences, University of Michigan, Ann Arbor

\section{Douglas Rumble, III}

Geophysical Laboratory, Washington, D.C.

The National Science Foundation (NSF) is a federal agency charged with the care and feeding of basic scientific research in U.S. colleges and universities. NSF is a major contributor toward the support of research in Earth, ocean, and atmospheric sciences, disciplines of great importance to AGU members.

NSF makes a regular practice of employing scientists from universities, nonprofit research organizations, industry, and state or local governments as temporary program of ficers ("rotators") with terms of service from $\mathrm{I}$ to 2 years. There are several reasons for the use of rotators:

- It brings to NSF people who have firsthand, recent knowledge of "what it is really like" beyond the Washington, D.C. beltway. Knowledge of new ideas, recent graduates, and a fresh look at the system are worth considerably more than the problems that arise owing to inexperienced program officers.

- It sheds some sunshine on internal NSF his tales to his home institution. procedures when the rotator returns with

\begin{abstract}
- It provides NSF management with considerable Hexibility in coping with changing staff requirements.
\end{abstract}

We recently served as rotating program officers ai $\mathrm{NS} \mathbf{r}$ under the Intergovernmental Personnel Act. The purpose of this report is to convey some of our experiences and impressions from working in three separate programs and divisions within the Geosciences (GEO) directorate of NSF. This may be of general interest to geoscientists unfamiliar with NSF's role in the community as well as to those who have considered or are considering becoming rotating program officers (rotators) at NSF. We have chosen a "roundtable" format in order to convey the common elements of our activities, experiences, and impressions but also to indicate their diversity. NSF is not monolithic but rather consists of many individual programs, each of which operates slightly differently.

- R. Batiza was a rotator in the Marine Geol ogy and Geophysics Program (MGG) of the Ocean Sciences Division (OCE) for 1 year (August 1985 to September 1986).

- D. Rea was with the Climate Dynamics Program (CDP) within the Division of Atmospheric Sciences (ATM) for 15 months

(May 1986 to August 1987)

- D. Rumble was with the Petrogenesis and Mineral Resources Program of the Earth Sciences Division (EAR) for 2 years (July 1985 to June 1987).

What did you do as a rotator?

Batiza: A large part of the rotator job in MGG is to handle the new proposals that ar rive by the truckload every few months or so. We also deal with problems/opportunities/

Cover. An exploratory seismic profile has been obtained by the French Compagnie Generale de Geophysique (CGG) in a joint experiment with the Museum $\mathrm{Na}$ tional d'Histoire Naturelle. The purpose of the experiment was not to explore the seabed, but to explore water mass structures in the deep Atlantic Ocean.

The seismic measurements were collected from 0000 to 1200 UT on May 6 , 1987 , by a CGG vessel, along a $100-\mathrm{km}-$ long track situated west of the Strait of Gibraltar, near the Gorringe Ridge (about $36^{\circ} \mathrm{N}-12^{\circ} \mathrm{W}$ ). The seismic equipment consisted of two components: an airgun sound source and a towed hydrophone array. The airgun produced a flat spectrum signal over the 10 - to $70-\mathrm{Hz}$ range. The hydrophone array was comprised of 120 hydrophones, which were mounted on a 3000-m-long, 16-m-deep towed streamer questions arising from ongoing and even concluded projects. These efforts are partly administrative and partly scientific because in addition to routine processing of proposals through the system, one has to read them and choose appropriate reviewers (following rather specific NSF guidelines). In the $M G G$ program we divided the proposal processing responsibilities among ourselves by subdiscipline. These responsibilities include communication with the principal investigators, helping with the scientific review/evaluation, and helping to make funding decisions. This part of the job is taxing because of the large volume of telephone and mail traffic and the diversity and complexity of issues that arise with individual proposals. Many scientists have their only contact with NSF at this level, so this part of the job is very important; it is often rewarding but (perhaps more so for the novice) can also be difficult and frustrating.

In addition to the daily processing and evaluation of proposals, there are many other activities in which program personnel participate. Some of these are related to internal NSF matters but others involve interagency programs or long-term scientific and budgetary planning. There are many opportunities for this sort of involvement; much of it is optional and requires individual initiative. In hindsight one of my personal regrets is not having taken greater advantage of these opportunities.

Reading many hundreds of proposals per year, communicating with dozens of scientists every day, conferring with other program officers in scientifically related programs (about joint-funding possibilities, for example), and attending many national and internal NSF meetings all combine to give any new rotator a broader perspective on their own field and related scientific disciplines. For the first 6 months, one is on a very steep learning curve. New rotators attend a week-long Program Manager's Seminar which is extremely interesting because it includes discussions with people from Congress, the Office of

Management and Budget, and other parts of NSF.

As a rotator, I probably spent about half my time on administrative items and the other half on scientific ones. Within MGG, program personnel must be aware of ship scheduling and other matters that are normally handled by the Facilities Section (versus the Research Section) of the Ocean Sciences Division. This, along with issues of equipment and development of new tools for research, add variety to the job. In general, of course, one's effectiveness in these areas, as well as in the areas of policy, budget, long-term planning, and interaction with the community, increase with experience, level of effort, and level within NSF hierarchy. My overall impression is that NSF is an unusually flexible organization. New ideas and input are solicited widely and carefully considered. Though funding decisions by program managers are carefully documented and reviewed at several levels, program personnel have a large measure of autonomy, especially in choosing how to set priorities among a great variety of

tasks. This means that the job of being an NSF rotator is in large measure defined by each individual rotator.

Rea: My responsibility within the CDP was to deal with the paleoclimatology projects that it funded. Paleoclimatology makes up about $35-40 \%$ of that program in terms of dollars, 
the remainder being the nature of modern climate and numerical modeling of present and past climates. About half my time was spent in the normal processing of proposals, somewhat less time than that of other program officers. CDP has no firm proposal deadlines, because they do not have panels so there is a relatively constant flux of new proposals throughout the year. Each of those requires the individual attention described above by Rodey Batiza.

A number of other efforts required the other half of my time at NSF. NSF encourages program officers to take a more active role in defining their own programs, not just averaging the review scores and funding on those rankings alone. Some of this is becoming ever more formalized, such as efforts toward minorities, women, undergraduates, etc., but the program officer needs to decide what is the most important science in terms of some point of reference and then act accordingly. In Paleoclimatology, that reference is the clear need of society to understand the changes in the Earth's environment that will be forthcoming in the next 50-100 years. Because of CDP's need to focus the program on climate change occurring at the various geological time scales and to make judgments on who is doing the best work on each aspect of this effort, the program officer needs to get to know the present and potential Principal Investigators (PIs). I accomplished this by traveling to large general meetings such as AGU or the American Meteorological Society where CDP PIs would be, to small meetings focused on topics of direct interest to the program, and to the home institutions of several individual PIs (site visits)

In a more proactive role, CDP organized a workshop for its PIs entitled Workshop on Paleoclimate Data-Model Interaction. The intent of this effort was to bring together and foster interaction among scientists who generate proxy data on the nature of past climates and climate change with those who develop computer-based mathematical models of climatic regimes. Organizing, running, and writing up the results of that meeting took much more time than I anticipated, a number of weeks all together, even though all three program managers in CDP participated in these efforts.

Two other aspects of my job as CDP Associate Program Director required significant amounts of time. One was involvement in th long-term planning and budgeting process that goes on every year at NSF. Program managers have learned that in these days of tighter monies, about the only way to get a significant increase in one's budget is to respond to scientific and community needs by helping to develop "initiatives" and work to have them adopted by the GEO as one of their top priorities. There are various ave nues to success in these efforts; the shortterm payoff is minimal, but in the long run the efforts can be fruitful. Last budget season there were several initiatives that dealt with one aspect or another of paleoclimatology developed and adopted by GEO. Working on these documents and adhering to the constraints of the system (i.e., to present largescale concepts in what eventually must boil down to only two pages) lends a useful understanding to just how NSF long-range planning functions

The last aspect of my job that is amenable to categorization was liaison between NSF and other scientifically oriented agencies, such as the National Oceanic and Atmospheric Administration, National Aeronautics and Space Administration, U.S. Geological Survey, the Office of Naval Research, the National Research Council/National Academy of Science, etc. I learned (no surprise) that in Washington much of this interaction occur among a group of science managers at the various agencies who generally know each other. Finally, C.DP has commitments to assis either the Foundation or other agencies of the government in dealing with both interna tional scientific societies and other governments. Individual CDP program managers traveled to both China and the U.S.S.R. in various official capacities during my tenure there.

Rumble: The Earth Sciences Division (EAR) is organized in two units, a major projects one that includes the Consortium for Continental Reflection Profiling, Deep Observation and Sampling of the Earth's Continental Crust, and Incorporated Research Institutions for Seismology) and Instrumentation and Facilities programs and a unit to suppor research of individual investigators. The latter includes the program of which I was director, Petrogenesis and Mineral Resources (PM). Because EAR is budgeted according to subdisciplines, rotators have full responsibilit as program directors. The chief duty of rotators in EAR, and the most time consuming, is processing proposals. The importance of carefully reading proposals and the necessity of collateral reading in subdisciplines outside one's expertise cannot be overemphasized. I found the reading job very rewarding and tried to benefit from it as one would from at tending a graduate seminar in "state-of-theart" petrology, geochemistry, and ore deposits research

Proposal processing continues with the pro gram director serving as recording secretary of proposal review panel meetings where a ranked list of proposals is debated. Budget negotiations follow the established sequence of the ranked list. A key issue in negotiating budgets is whether to fund fully top-ranked proposals or to cut budgets in order to be able to support a larger number of projects. In view of a sharply declining success ratio in PM, I took the position, supported by the proposal review panel, of asking top-ranked principal investigators to give up some of their requested funds so that lower ranked but meritorious proposals could be funded.

A most demanding aspect of a rotator's job is dealing with principal investigators whose proposals have been declined. A success rate that has declined into the $20 \%$ range means that most scientists who a program director talks to are disgruntled. There is no proper remedy to the problem immediately available short of printing more money. I tried, however, to help people who had been declined to overcome their resentments, to offer constructive criticism, and to encourage them to submit improved proposals.

What are some of the major issues of concern that one has to deal with as an NSF rotator?

Batiza: Since rotators at NSF, like permanent program personnel, have a great deal of contact with individual scientists daily, they have a good vantage point for assessing gen- eral community attutudes. Lately, of course. the major issue a rotator confronts on a daily basis is the shortage of money to fund an increasing number of excellent research proposals. No one is more keenly aware of this problem than the program officer because no one else in the system (even review panel members) has to grapple with the twin issues of "scientific merit" and limited funds at the level of choosing among individual research proposals. To further complicate matters, many other criteria may, in some cases, be used to make funding decisions, including disciplinary program balance, total level of funding that a PI may have, whether a proposal qualifies for certain NSF-wide special focus programs, whether the proposal is from a young investigator, ship schedules, and other considerations. Fairly strict guidelines for proposal evaluation and funding exist, and the decisions of program officers are carefully reviewed at several levels. Funding decisions are difficult to make because one is always trying to maximize the benefit using a very wide range of different criteria.

Scarce resources and increased competition fo funding are healthy, but only up to a certain point. My feeling is that most scientists spend too much time writing increasing numbers of proposals to fund their research. In principle, it would be better to spend this time writing fewer numbers of (hopefully) higher-quality proposals. However, most scientists perceive the system as a numbers game; more proposals submitted means a greater chance of success. In fact, this is probably not true, but there are several real factors which may contribute to this misconception: not all highly rated proposals are funded because of scarce resources; resubmittals of the same proposal may get higher or lower ratings than the original proposal; and funding decisions, at least in $M G G$, are made only 2 or 3 times a year, not continuously. This batch processing mode means that proposals are compared mostly with other proposals submitted at the same time and less so with those from previous panels. Since the mix of proposals varies from panel to panel, any high-quality proposal may fare slightly differently depending on the particular mix at a specific panel. These factors and the variety of criteria used for funding decisions can result in a perceived "random element" within the peer review/panel/program evaluation and funding system. This "random element" is often misinterpreted and, unfortunately, can lead to the perception that the system functions as a dart board.

Clearly, the issue of scarce resources and concerns about the peer review system cannot be satisfactorily resolved at the program staff level. Even so, program officers serve an important role in helping to educate individual members of the community on how the system works. My overall impression is that while the system is certainly not flawless (but how does one objectively and quantitatively measure its success?), it generally works very well. Largely, this is due to the careful efforts of mail reviewers and panelists, but also it is because NSF is staffed by talented and dedicated scientists and administrators who take their responsibilities very seriously.

Other issues of daily concern include those of "big" versus "small" science, the question of attracting talented young investigators into ocean sciences, the crucial need for long-term planning (both scientific and budgetary), the 
issue of high-risk, innovative science versus low-risk science, the problem of dwindling amounts of ship time for field programs, the problem of "soft-money" researchers who must pay their entire salary from grants, the problem of diminished funding for graduate students, postdoctorals, and new equipment and a host of others. In short, the program officer (and rotator) is concerned with all issues that affect the health and vigor of research in their program. Obviously, rotators going to NSF for periods of $1-3$ years cannot hope to solve these problems singlehandedly, but their input is solicited and can be helpful in finding long-term solutions.

Rea: The single largest issue of concern is how to deal with the present situation of far more good proposals than there is money to fund them. Rodey Batiza has discussed this issue at some length so I will be brief here. In the past, CDP has tended toward the less used option in NSF, that of funding fewer programs well enough to do the job proposed, rather than trimming everyone to spread the dollars further around the community. Recent increased budgetary restrictions, however, bring more and more trimming. We try to balance "big science" versus "small science" and hard-money versus softmoney investigators. We learn very quickly that high-quality science is accomplished both by single PIs and by multiinvestigator and multiinstitutional efforts. Larger groups, if well structured, can accomplish things that one or two PIs can never aspire to, but the problem is to find the proper balance for one's own program. An investigator with a soft-money appointment may need as much as twice the budget to accomplish the same amount of science as those with hard-money jobs and university support for students. Program managers try not to be influenced by budget levels in their initial evaluations but such idealism can not always be achieved.

There are a number of lesser concerns. One is how to identify high-risk/high-reward proposals; program managers are encour aged to fund such items occasionally. NSF program managers try hard to ensure funding for students and are concerned by the number of proposals that request technician funding but not student support. There is a concern about the growth of the bureaucracy and the increasing amounts of paperwork. Much of this is at the behest of Congress who requests agencies to gather all kinds of information. Most "helpful" changes within NSF require either an additional form to be completed and filed in the proposal jacket or re quire the program manager to provide some additional documentation. All these changes make the task of the program manager more ponderous.

Rumble: A major issue of concern, confronted on a daily basis, is the question "Did my proposal get a fair review?" NSF has instituted a number of regulations designed to minimize the possibility of prejudicial review. Conflicts of interest rules prohibit a rotator from handling or even discussing a proposal from his home institution. Similar restrictions apply to proposals received from former professors or students and from those with whom one has collaborated on a project or written a book, article, report, or paper with in the past 48 months. These same rules are taken into account when choosing ad hoc revin ${ }^{\circledR}$ ers. Members of proposal review panels who have a conflict of interest are excused from discussion and voting on such proposals

NSF procedures, likewise, are intended to promote an unprejudiced review of proposals. The use of proposal review panels puts a direct check on decisions by program directors. Open discussions in panel meetings where opinions have to be defended out loud inhibit favoritism or cronyism. Review of funding decisions is provided by the Division Director and his Deputy, by NSF's Division of Audit and Oversight, and by the Advisory Committee of Earth Sciences. The Advisory Committee, a body distinct from the proposa review panel, frequently examines in detail selected programs to verify that meritorious proposals are funded.

The current situation of increased proposal pressure, less rapidly increasing budget appropriations, and declining success rates im poses heavy burdens on individual investigators and program directors. Scientists are being asked to review more proposals but their own stand less of a chance of being funded.

The process of deciding what does and what doesn't get funded is overloaded. At a succes rate of $20 \%$, choices inevitably have to be made between equally valuable proposals, coloring funding decisions with an apparent arbitrariness. The problem is not with the quality of proposals approved for funding; they have survived a rigorous selection procedure and have achieved consensus endorsement from reviewers, panelists, and program direc tors. The problem is that our programs are underfunded in relation to the exciting research opportunities raised by new ideas and new instruments.

What are your overall impressions of NSF and its role in the community? Was your experience at NSF valuable?

Batiza: Overall, my impressions of NSF are very positive. While being a rotator involves doing a certain amount of routine paper shuffling, one has great freedom in choosing how to spend one's time. For example, during the first couple of months that I was at NSF, I was able to work on my own research at least 1 day each week. There are many negative misconceptions about the way NSF functions and, before my arrival, I expected that these would be borne out. Instead, they were dispelled within the first few weeks. My respect and admiration for the organization grew as my appreciation for the problems in volved increased.

NSF plays a vital role in our community. It seems especially important that during times of very scarce resources such as now, the community work with NSF to successfully compete for funds with other disciplines. Be ing a rotator was a very valuable experience. In addition to learning more about the proposal evaluation and funding process, the job provided a new and broader perspective on the field of geosciences. Being a good program officer (and rotator) is a difficult, challenging and open-ended job. I would say that the ratio of rewards to frustrations is about equal to that in the academic world.

Rea: NSF distributes $95 \%$ of its total budget to the scientific community, a far higher percentage than any other agency. My single strongest impression of NSF was that the people "in the trenches," the program officers, are a hard working, capable, caring group. Investigators may not agree with the decisions they make, but those decisions are not made lightly or without knowledge of their ramifications. I left NSF with a much higher regard for the program officers than when I arrived. All of them struggle daily with the problems of good people, good proposals, and restricted budgets.

NSF role in the community is vital to the health of the nation's science. It is the only nonpolitical, nonapplied scientific funding agency doing much effective work in the geosciences and as such is highly respected by scientists both at home and abroad. The strength of the foundation lies in the peer review system. Therefore recent Congressional avoidance of that system in awarding large grants, based often on politics, is to be denigrated.

My experience at NSF was valuable to me for several reasons. First, it provided a clear understanding of the internal operations of the foundation, how planning is done, how decisions are made, and who makes them. I'm not sure that I can write a better proposal than before, that merely requires more time and effort, but I do know more about exactly how it will be judged and where the leading edge of my science is. Second, the chance to immerse oneself in the aura of Washington, enjoy all the wonderful galleries and museums, live with daily soap operas of Congressional hearings into various misbehaviors, learn why everyone seems to be a Redskins fanatic, observe the realities of Potomac Fever, and so on, is a unique educational experience. Finally, I don't think that there is a better way to get a clear and complete overview of the nature of U.S. science and scientists in the fields of interest to me. As a marine-based scientist, I was able to meet the broad range of paleoclimatologists who work on land, limnologists, palynologists, dendrochronologists, those who study the record in ice cores, those who construct all types of computer models of present and past climates, and people with a variety of other skills. It is probably this personal broadening that will be most rewarding in the long run

Rumble: EAR is responsive to the changing needs of scientific progress and is bound neither by tradition nor by an excessively bureaucratic attitude. Funding priorities are established not by administrative fiat but by consultation with individual scientists acting as ad hoc reviewers, panelists, program officers, or as a member of the Advisory Committee. The reports of the Board of Earth Sciences, National Research Council, are a leading consideration in establishing scientific and budgetary goals. Officers of NSF's Division of Grants and Contracts exemplify a refreshingly nonbureaucratic attitude. In dealing with the innumerable "special cases" that arise in grant administration, grants officers usually held that if there was good scientific justification for a particular budget action, a way would be found to do it.

I recommend serving a term as program officer very highly. You will make new friends and travel to new places. You will have the opportunity to advance the interests of your research community. Furthermore, the forced learning of subdisciplines not actively pursued since graduate school is effective at jolting one out of midcareer ruts.

\section{Acknowledgment}

We thank T. O. Wright for insisting that the article needed an introduction. 